\title{
Quercetin suppresses glomerulosclerosis and TGF- $\beta$ s signaling in a rat model
}

\author{
YIFAN LIU $^{1}$, ENLAI DAI ${ }^{1}$ and JING YANG ${ }^{2}$ \\ ${ }^{1}$ Cooperation of Chinese and Western Medicine Department, Gansu University of Chinese Medicine; \\ ${ }^{2}$ Department of Children Glomerular Disease, The Second Hospital of Lanzhou University, Lanzhou, Gansu 730000, P.R. China
}

Received December 1, 2017; Accepted March 6, 2019

DOI: $10.3892 / \mathrm{mmr} .2019 .10118$

\begin{abstract}
The transforming growth factor- $\beta$ (TGF- $\beta$ ) signaling pathway is an important regulatory pathway in renal fibrosis and is abnormally activated in glomerulosclerosis. Quercetin is a common Chinese herbal medicine and has been reported to inhibit TGF- $\beta$ signaling pathway activation. In the present study a glomerulosclerosis rat model was constructed and mice were treated with different concentrations of quercetin. Biochemical parameters, pathological indices and expression levels of TGF- $\beta$ signaling pathway-associated proteins were detected using immunohistochemistry and western blotting. It was demonstrated that quercetin significantly improved physiological indices and altered the expression levels of TGF- $\beta$ signaling pathway-associated proteins in rats with glomerulosclerosis. In conclusion, quercetin can regulate the TGF- $\beta$ signaling pathway and reduce the progression of glomerulosclerosis.
\end{abstract}

\section{Introduction}

Glomerulosclerosis (GS) is the final pathway leading to the loss of renal function caused by a phenotypic transition of mesangial cells and an increase in extracellular matrix formation (1). The lesions are characterized by a loss of podocytes $(2,3)$ and an accumulation of extracellular matrix (4). The effect

Correspondence to: Dr Enlai Dai, Cooperation of Chinese and Western Medicine Department, Gansu University of Chinese Medicine, 10 East of Dingxi Road, Lanzhou, Gansu 730000, P.R. China

E-mail: 442068478@qq.com

Abbreviations: TGF- $\beta$, transforming growth factor- $\beta$; GS, glomerulosclerosis; QU, quercetin; EMT, epithelial mesenchymal transition; FSP-1, fibroblast-specific protein-1; $\alpha$-SMA, $\alpha$-smooth muscle actin; ADR, adriamycin; SHO, sham operation group; UTP, urine total protein; TP, total protein; Abl, albumin; TG, triglyceride; TC, total cholesterol; BUN, urea nitrogen; SCr, serum creatinine; $\mathrm{H} \& \mathrm{E}$, hematoxylin and eosin; PAS, periodic acid-Schiff base; TBST, Tris-buffered saline containing Tween-20

Key words: quercetin, glomerulosclerosis, transforming growth factor- $\beta$ signaling pathway of these etiological factors manifest as changes to glomerular mechanics (including high glomerular filtration and pressure), metabolism (such as diabetes) and a variety of regulatory molecules (such as cytokines) (5-7). Transforming growth factor- $\beta$ (TGF- $\beta$ ) is a multifunctional cytokine that regulates cell proliferation, differentiation and apoptosis. It has been previously demonstrated that TGF- $\beta$ can promote renal fibrosis by stimulating the synthesis and inhibiting the degradation of the extracellular matrix (8). Furthermore, TGF- $\beta$ can induce podocyte apoptosis by activating the mothers against decapentaplegic homolog 9 (Smad) signaling pathway (9). Together, these results suggest that TGF- $\beta$ is an important pathogenic factor involved in the pathogenesis of GS. Thus, the treatment of GS with TGF- $\beta$ is currently being investigated.

Quercetin (QU) is a natural flavonoid that is present in various flowers, and leaves and fruits of plants (10). Recent pharmacological studies have demonstrated that QU exerts strong anti-tumor, anti-oxidant, anti-fibrosis and anti-viral effects by regulating the activity of multiple signaling pathways $(11,12)$. Another study suggested that QU inhibits the proliferation and invasion of prostate tumors by preventing TGF- $\beta$-induced epithelial mesenchymal transition (EMT) (13). EMT is a complex biological process in which epithelial cells are transformed into interstitial phenotypes with the loss of specific endothelial cell markers, including mesenchymal phenotype initiating expression of fibroblast-specific protein-1 (FSP-1) and $\alpha$-smooth muscle actin ( $\alpha$-SMA). In addition, QU reduces the expression of TGF- $\beta$ to inhibit renal interstitial fibrosis (14). Based on these results, QU may alleviate GS by inhibiting the TGF- $\beta$ signaling pathway.

In the present study, the mechanism and feasibility of QU treatment for GS were examined by evaluating the effects of QU on physiological parameters of GS mice and associated proteins in the TGF- $\beta$ signaling pathway.

\section{Materials and methods}

Animal model. A total of 60 male, 6-8 week old Sprague-Dawley rats, weighing $220 \pm 20$ g, were purchased from the Experimental Animal Center of Gansu University of Chinese Medicine (Lanzhou, China). The protocol was approved prior to commencing this study by the animal ethics committee of Gansu University of Chinese Medicine. All rats were housed under standard conditions (12/12 light/dark cycle, 
$40 \%$ humidity and $21-25^{\circ} \mathrm{C}$ ) and fed a standard rat diet. The rats were randomized into three groups: Control group (NC; $\mathrm{n}=10$ ), sham operation group ( $\mathrm{SHO} ; \mathrm{n}=10)$ and GS model group (GS; n=40). The GS group was prepared by uninephrectomy of the left kidney. Briefly, rats were anesthetized by intraperitoneal injection of $30-60 \mathrm{mg} / \mathrm{kg}$ pentobarbital. Following routine disinfection, an incision of $1-1.5 \mathrm{~cm}$ was made in the back to expose the kidney. The kidney fat and adrenal glands were stripped away, the left renal portal vessels were ligated, the left kidney was resected and the incision was sutured. Subsequently, these rats were treated with adriamycin (ADR; Shanxi Pude Pharmaceutical Co., Shanxi, China) at a dose of $3 \mathrm{mg} / \mathrm{kg}$ by single tail vein injection at days 8 and 29. The SHO group was operated on without removal of the kidney and received tail vein injection with saline solution, while the $\mathrm{NC}$ group was maintained under normal conditions without surgery or injection.

Drug treatment and biochemical analysis. A total of 30 randomly selected GS rats were divided equally into three groups $(n=10)$ and treated with different doses of QU (Sigma-Aldrich; Merck KGaA, Darmstadt, Germany) once daily by oral gavage for 8 weeks: Low-dose group (QU I, $25 \mathrm{mg} / \mathrm{kg} /$ day), intermediate-dose group (QU II, $50 \mathrm{mg} / \mathrm{kg} /$ day) and high-dose group (QU III, $100 \mathrm{mg} / \mathrm{kg} / \mathrm{day}$ ). The NC group, SHO group, GS group, QU I group, QU II group and QU III group were treated with equal volumes of saline solutions. Following 8 weeks of drug intervention, the mental status (15), activity, fur glossiness, appetite, defecation and weight alterations were observed and recorded for each group. The 24-h urine total protein excretion (UTP/24 h) was measured by the sulfosalicylic acid method. Briefly, $0.1 \mathrm{ml} 4 \%$ sulfosalicylic acid reagent was added to 2-3 $\mathrm{ml}$ of urine supernatant in a test tube. The tube was gently shaken for $1 \mathrm{~min}$ and immediately observed for turbidity. The blood was collected from the caudal vein of the rats and the levels of serum total protein (TP), serum albumin (Alb), triglyceride (TG), serum total cholesterol (TC), urea nitrogen (BUN), and serum creatinine ( $\mathrm{SCr}$ ) were measured with ELISA kits according to the manufacturer's protocol: Rat triglyceride (TG; RA20187); Rat Albumin (Alb; RA20636); Rat Total cholesterol (TC; RA20136); Rat creatinine (Cr; RA20115) from Bio-Swamp (Wuhan, Hubei, China). Rat total protein (TP; RJ16656) and Rat urea nitrogen (BUN; RJ16084) were purchased from Shanghai Renjie Biotechnology Co., Ltd. (Shanghai, China).

Pathological analysis. After rats in each group were anesthetized (pentobarbital, $45 \mathrm{mg} / \mathrm{kg}$, intraperitoneal injection) and rapidly sacrificed by cervical dislocation. These rats were sacrificed and the right kidneys were removed and fixed with $4 \%$ formaldehyde (Beijing Solarbio Science \& Technology Co., Ltd., Beijing, China) at $21-25^{\circ} \mathrm{C}$ for $15 \mathrm{~min}$. The kidney tissues were embedded in paraffin and $4-\mu \mathrm{m}$ sections were cut. Certain paraffin sections were separately stained with hematoxylin and eosin $(\mathrm{H} \& \mathrm{E} ; 1 \% \mathrm{H}$ for $7 \mathrm{~min}, 1 \% \mathrm{E}$ for $4 \mathrm{~min}$ at $21-25^{\circ} \mathrm{C}$ ), periodic acid-Schiff base (PAS; $1.1 \%$ Schiff's reagent for $30 \mathrm{~min}$ at $20^{\circ} \mathrm{C}$ ) and Masson's trichrome (Masson; $1 \% \mathrm{H}$ for $5 \mathrm{~min}, 1 \%$ Ponceau S for $7 \mathrm{~min}, 2 \%$ Aniline blue for $5 \mathrm{~min}$ at $21-25^{\circ} \mathrm{C}$ ). The remaining paraffin sections were dewaxed and microwaved for $10 \mathrm{~min}$ in citrate buffer for antigen retrieval. Next, the sections were treated with $3 \%$ hydrogen peroxide $\left(\mathrm{H}_{2} \mathrm{O}_{2}\right)$ in methanol at $21-25^{\circ} \mathrm{C}$ for 30 min to block the activity of endogenous peroxidase followed by rinsing in PBS three times. The sections were incubated with antibodies (Abcam, Cambridge, UK) against podocyte marker proteins [zona occludens protein 1 (ZO-1; 1:100; cat. no. ab214228), Nephrin (1:2,000; cat. no. ab216341) and P-cadherin (1:100; cat. no. ab137729)], EMT marker proteins [ $\alpha-S M A ~(1: 50$; cat. no. ab5694) and FSP-1 (1:2,000; cat. no. ab197896)] and TGF- $\beta$ and its associated signaling pathway proteins $[\mathrm{TGF}-\beta$ receptor 1 (TGFBR1; 1:50; cat. no. ab31013), TGFBR2 (1:100; cat. no. ab186838), Smad2/Smad3 (1:100; cat. no. ab217553), Smad4 (1:100; cat. no. ab40759), Smad7 (1:100; cat. no. ab216428), glycogen synthase kinase (GSK)-3 $\beta$ (1:50; cat. no. ab75745) and $\beta$-catenin (1:500; cat. no. ab32572)] overnight at $4^{\circ} \mathrm{C}$. Next, goat anti-rabbit-horseradish peroxidase (HRP)-conjugated IgG antibody (1:1,000; cat. no. ab6721; Abcam) was added for $1 \mathrm{~h}$ at $37^{\circ} \mathrm{C}$. Finally, the sections were developed with $1 \%$ diaminobenzidine for $5 \mathrm{~min}$, counterstained with $1 \%$ hematoxylin for $2 \mathrm{~min}$ at $21-25^{\circ} \mathrm{C}$ and mounted with neutral gum. Images of the sections were captured at magnification, $\mathrm{x} 400 \mathrm{using}$ a BX53 inverted light microscope (Olympus Corporation, Tokyo, Japan).

$R N A$ extraction and reverse transcription-quantitative polymerase chain reaction ( $R T-q P C R)$. Total RNA was extracted from the kidney tissue using TRIzol (Invitrogen; Thermo Fisher Scientific, Inc., Waltham, MA, USA) and reverse transcription synthesis of cDNA was performed in a single-step method using the Eastep ${ }^{\circledR}$ RT Master Mix kit (Promega Corporation, Madison, WI, USA), according to the manufacturer's protocol. qPCR was performed using the GoTaq ${ }^{\circledR}$ 2-Step RT-qPCR System (Promega Corporation) following the manufacturer's protocol. The thermocycling conditions for RT-qPCR were $5 \mathrm{~min}$ at $99^{\circ} \mathrm{C}$, then $15 \mathrm{sec}$ at $94^{\circ} \mathrm{C}, 30 \mathrm{sec}$ at $59^{\circ} \mathrm{C}$ (40 cycles), $45 \mathrm{sec}$ at $72^{\circ} \mathrm{C}$. The fold-change in mRNA expression was calculated with the $2^{-\Delta \Delta \mathrm{Cq}}$ method (16). Primer sequences are presented in Table I.

Western blotting. Total protein was extracted from renal tissue using radioimmunoprecipitation assay buffer (Beyotime Institute of Biotechnology, Shanghai, China) and protein concentration was determined using bicinchoninic protein assay reagent (Beyotime Institute of Biotechnology). First, $20 \mu \mathrm{g}$ protein sample were separated by $10 \%$ SDS-PAGE (Beijing Solarbio Science \& Technology Co., Ltd.) and transferred to polyvinylidene fluoride membranes (EMD Millipore, Billerica, MA, USA), and then blocked using 5\% non-fat milk-Tris-buffered saline containing $0.05 \%$ Tween 20 (TBST) at $21-25^{\circ} \mathrm{C}$ for $2 \mathrm{~h}$. Following washing with TBST, the membranes were incubated with primary antibodies at $4^{\circ} \mathrm{C}$ overnight, the primary antibodies were as follows: Anti-TGF- $\beta 1$ (1:500; cat. no. ab92486; Abcam); anti-ZO1 (1:1,000; ab96587; Abcam); anti-Nephrin (1:1,000; cat. no. ab216341; Abcam); anti-P-cadherin (1:2,000; cat. no. ab137729; Abcam); anti- $\alpha$-SMA (1:100; cat. no. ab5694; Abcam), anti-FSP-1 (1:1,000; cat. no. ab197896; Abcam); anti-TGFBR2 (1:1,000; cat. no. ab186838; Abcam), anti-TGFBR1 (1:200; cat. no. ab31013; Abcam), anti-Smad2/Smad3 (1:1,000; cat. no. ab202445; Abcam), anti-Smad4 (1:5,000; cat. no. ab40759; 
Table I. Primer sequences of the glomerulosclerosis associated proteins.

\begin{tabular}{|c|c|}
\hline Gene & Primer sequence \\
\hline \multirow[t]{2}{*}{ TGF- $\beta 1$} & F: 5'-ATGAACCGACCCTTCCTGCT-3' \\
\hline & R: 5'-TGTGTCCAGGCTCCAAATGT-3' \\
\hline \multirow[t]{2}{*}{ Smad7 } & F: 5'-CTCTTGCGAACATTACGGCT-3' \\
\hline & R: 5'-CGAGATCAAGGTCGACCTGC-3' \\
\hline \multirow[t]{2}{*}{ GADPH } & F: 5'-CTACCCACGGCAAGTTCAAT-3' \\
\hline & R: 5'-GGATGCAGGGATGATGTTCT-3' \\
\hline \multirow[t]{2}{*}{$\operatorname{Smad} 2 / 3$} & F: 5'-GGAAAGGGTTGCCACATGTT-3' \\
\hline & R: 5'-AGAATCTCCGTGTGCCGAGG-3' \\
\hline \multirow[t]{2}{*}{ Smad4 } & F: 5'-ACGGCCATCTTCAGCACCAC-3' \\
\hline & R: 5'-AGAATGCACAATCGCCGGAG-3' \\
\hline \multirow[t]{2}{*}{$\mathrm{ZO}-1$} & F: 5'-GGCATTATTCGCCTTCATAC-3' \\
\hline & R: 5'-GGAACACAACAATCGGATAC-3' \\
\hline \multirow[t]{2}{*}{ GSK3 $\beta$} & F: 5'-CTTCAGGACAAGCGATTTA-3' \\
\hline & R: 5'-CCAGCACCAGGTTAAGGTAG-3' \\
\hline \multirow[t]{2}{*}{ Nephrin } & F: 5'-CCCTCCGGGACCCTACTG-3' \\
\hline & R: 5'-TCTGGGAGGATGGGATTGG-3' \\
\hline \multirow[t]{3}{*}{ P-Cadherin } & F:5'-AAGTGCTGCAGCCAAAGACAGA-3 \\
\hline & R: 5'-AGGTAGACCCACCTCAATCATC \\
\hline & CTC-3' \\
\hline \multirow[t]{2}{*}{ SMA } & F: 5'-CAGCTATTGCCGTTCCAATTGA-3' \\
\hline & R: 5'-CCAGGGCTTCATCATTGCA-3' \\
\hline \multirow[t]{2}{*}{ FSP } & F: 5'-ATACTCAGGCAACGAGGGTG-3' \\
\hline & R: 5'-CTTCCGGGGCTCCTTATC-3' \\
\hline \multirow[t]{2}{*}{ TGF- $\beta$ IR } & F: 5'-ACCATTTGGAGCCAGAACAC-3' \\
\hline & R: 5'-GGTCTGAAGAGCTGAGCCTG-3' \\
\hline \multirow[t]{4}{*}{ TGF- $\beta$ IIR } & F: 5'-CGAGCTCGGTGGAAGGTCTCATTT \\
\hline & TATTG-3' \\
\hline & R: 5'-CCCAAGCTTGGGATGTAAAAGAC \\
\hline & AAACAATG-3' \\
\hline \multirow[t]{3}{*}{$\beta$-catenin } & F: 5'-GCTGACCAAAACTGCTAAATGAC \\
\hline & GA-3' \\
\hline & R: 5'-TGTAGGGTCCCAGCGGTACAA-3' \\
\hline
\end{tabular}

ZO-1, zona occludens protein 1; Smad, mothers against decapentaplegic homolog 9; GSK, glycogen synthase kinase; TGF- $\beta$ R, tumor growth factor $\beta$ receptor; SMA, smooth muscle actin; FSP, fibroblast-specific protein.

Abcam), anti-Smad7 (1:500; cat. no. ab216428; Abcam), anti-GSK-3 $\beta$ (1:1,000; cat. no. ab75745; Abcam), anti- $\beta$-catenin (1:5,000; cat. no. ab32572; Abcam) and anti-GAPDH (1:2,500; cat. no. ab9485; Abcam), followed by incubation with an HRP-conjugated secondary antibody (1:10,000; cat. no. ab6721; Abcam) for $1 \mathrm{~h}$ at room temperature. Finally, proteins were visualized by enhanced chemiluminescence ECL (cat. no. WBKLS0010; EMD Millipore). The images were acquired and analyzed with a ChemiDoc Touch imaging system (Bio-Rad Laboratories, Inc., Hercules, CA, USA).

Statistical analysis. The results of immunohistochemistry and western blotting were analyzed using Image $\mathbf{J}$ software version 1.8.0 (National Institute of Health, Bethesda, MD, USA). The results are expressed as the mean \pm standard deviation and each experiment repeated three times. Significant differences were established by one-way analysis of variance followed by Bonferroni post-hoc test using the GraphPad Instat program version 3.0 (GraphPad, Inc., La Jolla, CA, USA). $\mathrm{P}<0.05$ was considered to indicate a statistically significant difference.

\section{Results}

General appearance. Rats in the $\mathrm{NC}$ and $\mathrm{SHO}$ groups consumed a normal diet and exhibited increased weight, good mental status, sensitive response, shiny fur and solid stools; there was no significant difference between these two groups (data not shown). Serum biochemical indexes also exhibited no significant difference between these two groups (Table II). Therefore, the operation did not affect the experiment. Rats in the GS groups demonstrated decreased food intake and became lethargic, dispirited, and unresponsive. Additionally, they demonstrated severe alopecia, dark hair, loose stools, discolored urine and reduced weight. The levels of serum TP and Alb significantly decreased, but TG, TC, BUN, SCr and UTP significantly increased compared with the NC and SHO groups. Following QU intervention in rats with GS, compared with in the GS group, the general appearance of rats (QU I, QU II and QU III groups) was improved in a dose-dependent manner. The general appearance of the rats in the QU III group was near normal levels. The levels of serum TP and Alb were significantly increased, and TG, TC, BUN, SCr and UTP significantly decreased in a dose-dependent manner in the QU I, QU II and QU III groups compared with the GS group (Table II).

Biochemical parameters. Following 8 weeks of the study, there was no significant difference in biochemical parameters between the NC group and SHO group ( $\mathrm{P}>0.05$; Table II). The effect of the surgery on the experiment can be considered insignificant. Compared with the SHO group, the weight of mice in the GS group was significantly reduced, while kidney weight increased $(\mathrm{P}<0.05$; Table II). UTP in the GS group increased by $\sim 10$-fold, accompanied by increased levels of TG, $\mathrm{CHO}, \mathrm{BUN}$ and SCr and significantly decreased levels of TP and Alb $(\mathrm{P}<0.05$; Table II) in comparison to $\mathrm{NC}$ and SHO. Biochemical parameters, including TG, Alb, TC, BUN and $\mathrm{SCr}$ in rats with GS returned to nearly normal levels following treatment with QU III.

Pathological evaluation. Based on direct observation, compared with the normal group, the kidneys of the GS group were fibrotic (Fig. 1A). Additionally, enlargement, damage, atrophy and hardening of the glomerulus, and interstitial lymphocytic infiltration in the GS group were observed by H\&E staining (Fig. 1B). In addition, Masson staining demonstrated that the interstitial cells of the renal interstitium proliferated, the mesangial area increased in mass and the basement membrane of the glomerulus exhibited focal proliferation in the GS group compared with sham and NC rats (Fig. 1C). PAS staining demonstrated that the basement membrane of GS group rats became wider and the 
Table II. Biochemical parameters in all groups.

\begin{tabular}{|c|c|c|c|c|c|c|}
\hline Parameter & $\mathrm{NC}$ & $\mathrm{SHO}$ & GS & QU I & QU II & QU III \\
\hline Kidney (g) & $1.11 \pm 0.02$ & $1.20 \pm 0.09^{b}$ & $2.45 \pm 0.26^{\mathrm{a}, \mathrm{c}}$ & $2.40 \pm 0.26^{\mathrm{c}, \mathrm{f}}$ & $2.22 \pm 0.15^{\mathrm{c}, \mathrm{e}}$ & $1.97 \pm 0.14^{\mathrm{c}, \mathrm{e}}$ \\
\hline Weight (g) & $442.00 \pm 25.68$ & $451.80 \pm 21.08^{b}$ & $370.71 \pm 19.97^{\mathrm{a}, \mathrm{c}}$ & $388.29 \pm 14.43^{\mathrm{c}, \mathrm{f}}$ & $383.61 \pm 18.23^{\mathrm{c}, \mathrm{e}}$ & $416.42 \pm 10.45^{\mathrm{c}, \mathrm{e}}$ \\
\hline $\mathrm{TP}(\mathrm{mM})$ & $62.00 \pm 3.19$ & $60.78 \pm 2.08^{\mathrm{b}}$ & $52.90 \pm 2.24^{\mathrm{a}, \mathrm{c}}$ & $61.46 \pm 4.25^{\mathrm{c}, \mathrm{e}}$ & $57.91 \pm 2.91^{\mathrm{c}, \mathrm{e}}$ & $60.61 \pm 1.80^{\mathrm{d}, \mathrm{e}}$ \\
\hline TG (mM) & $1.24 \pm 0.17$ & $1.60 \pm 0.23^{b}$ & $12.30 \pm 1.73^{\mathrm{a}, \mathrm{c}}$ & $6.99 \pm 0.36^{\mathrm{c}, \mathrm{e}}$ & $4.64 \pm 1.87^{\mathrm{c}, \mathrm{e}}$ & $2.31 \pm 0.32^{\mathrm{c}, \mathrm{e}}$ \\
\hline $\mathrm{Alb}(\mathrm{g} / \mathrm{l})$ & $38.08 \pm 1.49$ & $36.06 \pm 1.22^{\mathrm{b}}$ & $14.20 \pm 1.24^{\mathrm{a}, \mathrm{c}}$ & $22.37 \pm 2.11^{\mathrm{c}, \mathrm{e}}$ & $23.15 \pm 4.35^{\mathrm{c}, \mathrm{e}}$ & $30.84 \pm 1.72^{\mathrm{c}, \mathrm{e}}$ \\
\hline $\mathrm{TC}(\mathrm{mM})$ & $1.17 \pm 0.04$ & $1.48 \pm 0.09^{\mathrm{b}}$ & $10.60 \pm 0.98^{\mathrm{a}, \mathrm{c}}$ & $5.42 \pm 0.43^{\mathrm{c}, \mathrm{e}}$ & $5.03 \pm 1.01^{\mathrm{c}, \mathrm{e}}$ & $2.76 \pm 0.23^{\mathrm{c}, \mathrm{e}}$ \\
\hline BUN (mM) & $5.64 \pm 0.43$ & $6.38 \pm 0.42^{b}$ & $17.39 \pm 2.53^{\mathrm{a}, \mathrm{c}}$ & $12.67 \pm 0.58^{\mathrm{c}, \mathrm{e}}$ & $11.03 \pm 1.03^{\mathrm{c}, \mathrm{e}}$ & $8.99 \pm 0.43^{\mathrm{c}, \mathrm{e}}$ \\
\hline $\mathrm{SCr}(\mathrm{mM})$ & $29.40 \pm 1.71$ & $33.40 \pm 1.98^{\mathrm{b}}$ & $98.57 \pm 10.36^{\mathrm{a}, \mathrm{c}}$ & $71.57 \pm 443^{\mathrm{c}, \mathrm{a}}$ & $67.06 \pm 8.60^{\mathrm{c}, \mathrm{e}}$ & $45.29 \pm 3.04^{\mathrm{c}, \mathrm{e}}$ \\
\hline UTP (mg/24 h) & $31.34 \pm 2.59$ & $34.66 \pm 4.97^{\mathrm{b}}$ & $363.19 \pm 18.21^{\mathrm{a}, \mathrm{c}}$ & $299.84 \pm 20.13^{\mathrm{c}, \mathrm{e}}$ & $310.53 \pm 28.63^{\mathrm{c}, \mathrm{e}}$ & $267.70 \pm 12.61^{c, e}$ \\
\hline
\end{tabular}

${ }^{\mathrm{a}} \mathrm{P}<0.05$ vs. the $\mathrm{NC} ;{ }^{\mathrm{b}} \mathrm{P}>0.05$ vs. $\mathrm{NC} ;{ }^{\mathrm{c}} \mathrm{P}<0.05$ vs. $\mathrm{SHO} ;{ }^{\mathrm{d}} \mathrm{P}>0.05$ vs. $\mathrm{SHO} ;{ }^{\mathrm{e}} \mathrm{P}<0.05$ vs. GS; ${ }^{\mathrm{f}} \mathrm{P}>0.05$ vs. GS. TP, serum total protein; TG, triglyceride; $\mathrm{Alb}$, serum albumin; TC, serum total cholesterol BUN, urea nitrogen; $\mathrm{SCr}$, serum creatinine; UTP, urine total protein; QU, quercetin; NC, normal control; SHO, sham operation group; GS, glomerulosclerosis.
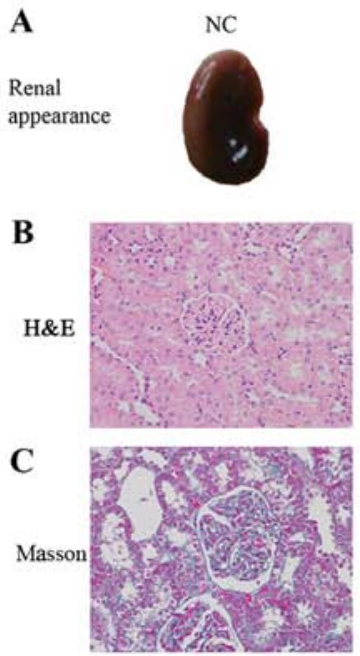

D

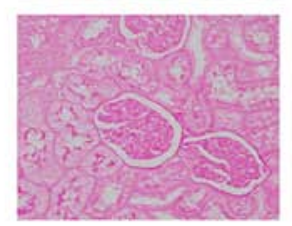

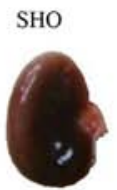
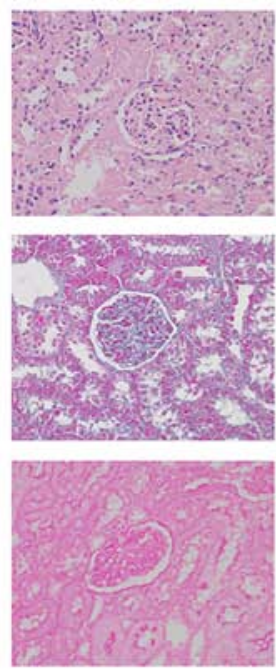

GS
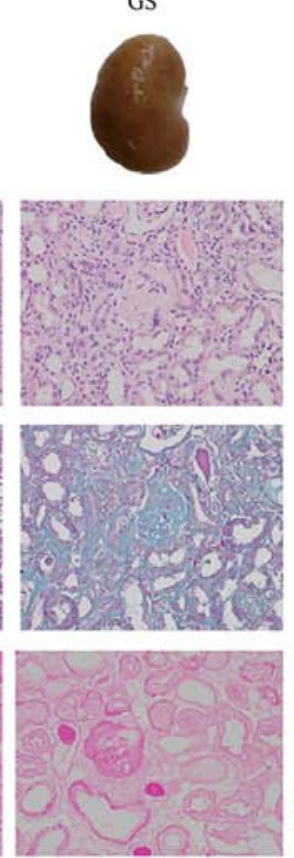
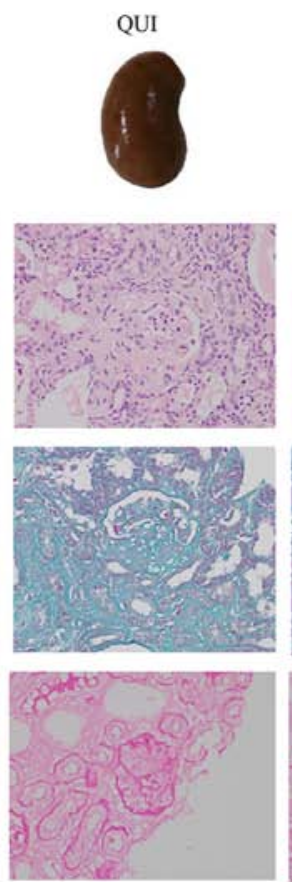

QUII
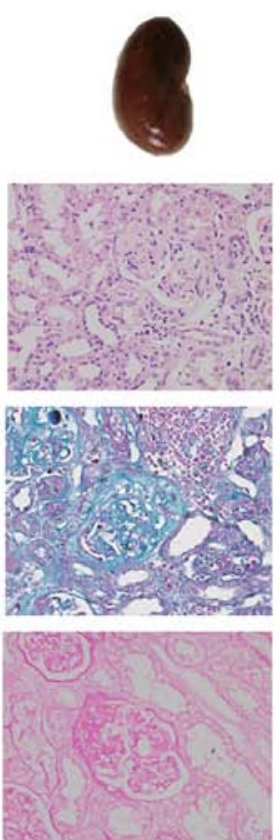

QUIII
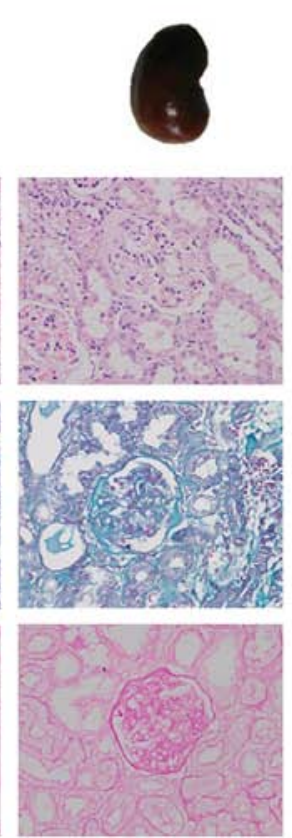

Figure 1. Pathological analysis of renal tissue following QU treatment in rats. (A) Observation of renal tissue in rats. (B) H\&E, (C) Masson and (D) PAS staining of rat kidney tissue in all groups, magnification, x400. NC, normal control; SHO, sham operation group; GS, glomerulosclerosis; QU, quercetin; QU I, QU 25 mg/kg/day; QU II, 50 mg/kg/day; QU III, 100 mg/kg/day; H\&E, hematoxylin and eosin; PAS, periodic acid-Schiff base.

mesangial matrix increased compared with sham and NC rats (Fig. 1D). Following treatment with increasing doses of QU, it was observed that the pathological alterations of renal tissue were gradually relieved and the fibrosis status of the kidneys gradually subsided and became normal in the QU-treated group.

Effect of $Q U$ on transcription and translation levels of $G S$-associated proteins. mRNA and protein in kidney tissue from each group were extracted and detected by RT-qPCR, western blotting, and immunohistochemistry. Podocyte marker proteins (ZO-1, Nephrin and P-cadherin) and Smad7 mRNAs (Fig. 2A) exhibited significantly decreased expression in the GS group compared with the NC group $(\mathrm{P}<0.001)$. Similarly, at the translation level, these proteins exhibited low expression (Fig. 2B) and distribution in the GS group. The proteins were recovered following QU treatment and their levels were altered in a dose-dependent manner. By contrast, EMT marker proteins ( $\alpha$-SMA and FSP-1) and other TGF- $\beta$ signaling pathway-associated proteins (TGFBR2, TGFBR2, Smad2/Smad3, Smad4, GSK-3 $\beta$ and $\beta$-catenin) exhibited increased expression in the GS group compared with the NC group (Fig. 3), and distribution (Fig. 4) of these proteins observed by immunohistochemistry exhibited similar results. Following QU treatment, protein expression decreased in a dose-dependent manner. 
A

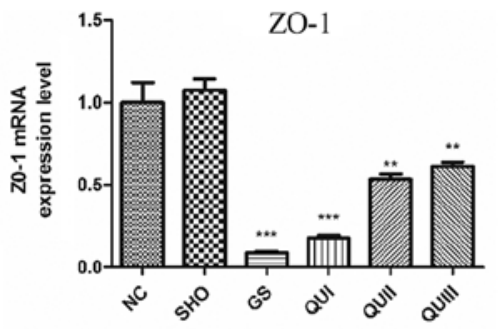

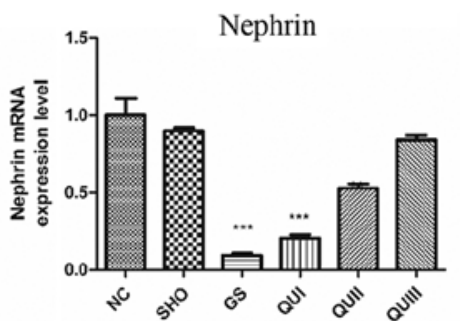
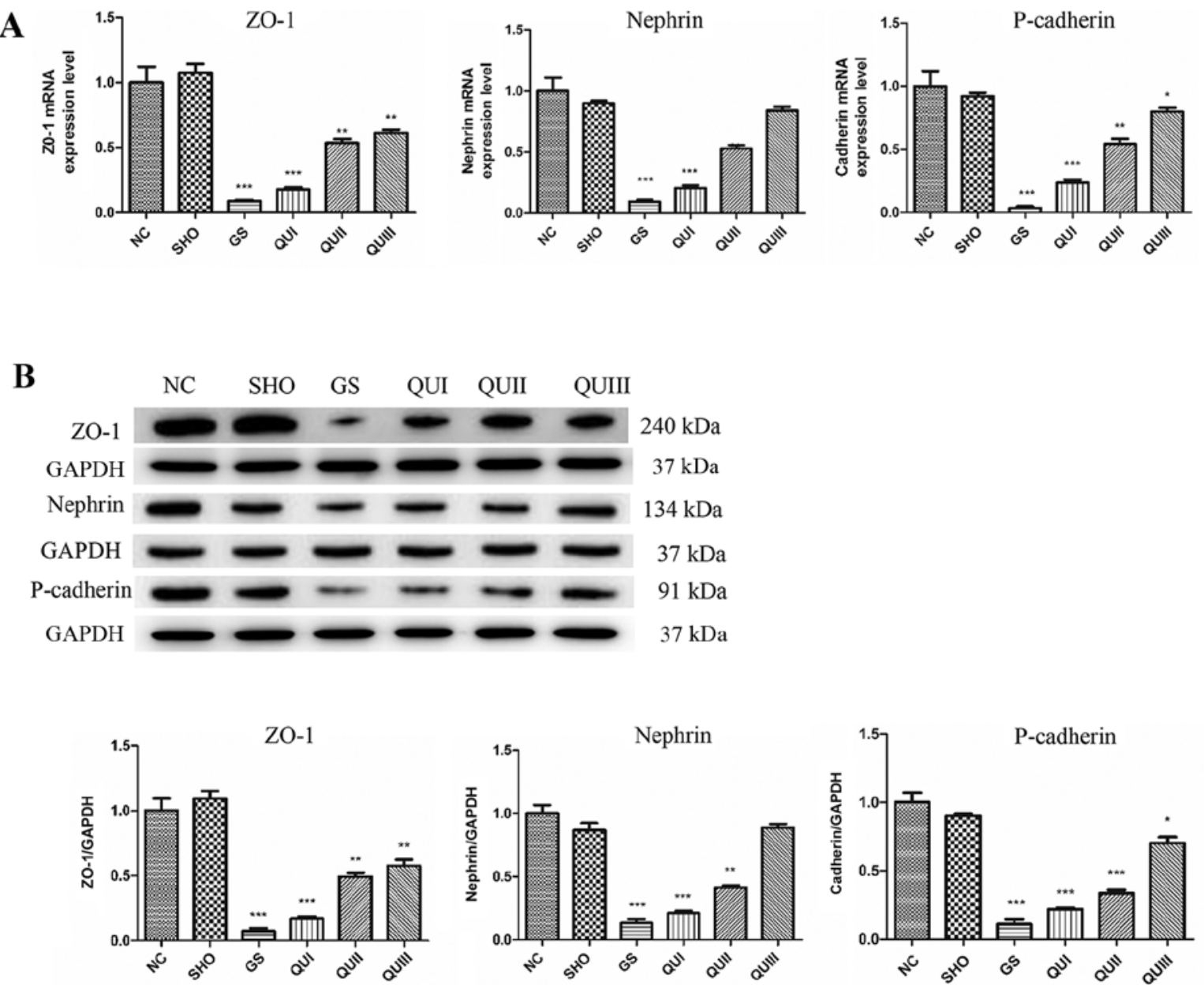

Figure 2. Expression levels of ZO-1, Nephrin and Cadherin following QU intervention. (A) mRNA and (B) protein expression levels were detected by RT-qPCR and western blotting, respectively. All data are presented as the mean \pm standard deviation of the mean. ${ }^{*} \mathrm{P}<0.05$, ${ }^{* * *} \mathrm{P}<0.01$ and ${ }^{* * *} \mathrm{P}<0.001$, vs. the $\mathrm{NC}$ group. ZO-1, zona occludens protein 1; NC, normal control; SHO, sham operation group; GS, glomerulosclerosis; QU, quercetin; QU I, QU 25 mg/kg/day; QU II, $50 \mathrm{mg} / \mathrm{kg} /$ day; QU III, $100 \mathrm{mg} / \mathrm{kg} /$ day.

\section{Discussion}

To investigate the efficacy and mechanism of QU in GS, an ADR-induced GS mouse model (GS group) was constructed which demonstrated similarities to human renal disease (17). The main experimental manifestations of these mice were proteinuria, hyperlipidemia, hypoproteinemia, hypoxemia and renal hypofunction $(18,19)$. Accordingly, certain biochemical indices of the mice were altered, such as increased SCr, BUN, TG and UTP (20). In the present study, the associated biochemical indices (SCr, BUN, TC, TG, UTP, TP and Alb) were examined following establishment of the rat model, and the results agreed with those of previous reports $(20,21)$. Together with the examination of general appearance and pathological sections of the mice, these results indicated that the renal system of rats in the GS group had swelling and fibrosis, their functions were severely impaired, and absorption and filtration capabilities were weakened. Following treatment with QU, the physiological indices of GS rats began to recover. Therefore, QU may be useful for in the treatment of GS. QU can promote the filtration, protein absorption and lipid metabolism in the kidney, as well as inhibit glomerular fibrosis and improve the renal function of glomerulosclerotic rats.
GS is associated with the activation of various cytokines signal transduction pathways. Numerous studies confirm that TGF- $\beta$ is a major cytokine causing GS (22-25). Therefore, TGF- $\beta$ and its signal transduction pathway have become important targets for studies of renal diseases caused by various factors (26). There are two main TGF- $\beta$ receptors: TGFBR2 and TGFBR1 (27). Activated TGF- $\beta$ can bind TGF-BR1 and then adsorb TGF-BR1 to form heterodimers on the cell membrane that activate downstream effectors. Activated TGFBR1 induces phosphorylation of Smad2 and Smad3, and the phosphorylation of Smad2 or Smad3 can bind Smad4 to form oligomers, followed by translocation into the nucleus to act as a transcription factor (28-30). However, Smad7 can inhibit the phosphorylation of Smad2 and Smad3 by directly interacting with the TGFBR, and ultimately block the TGF- $\beta$ signaling pathway (31). In the present study, the expression levels of TGFBR2, TGFBR1, $\mathrm{Smad} 2 / \mathrm{Smad} 3$ and Smad4 were elevated in the GS group, and the expression of Smad7 was inhibited. In addition, during EMT there was a significant increase in $\alpha$-SMA and FSP-1, which are transcriptionally regulated by the TGF- $\beta$ signal pathway to promote GS $(29,32)$. TGF- $\beta$ signaling can 

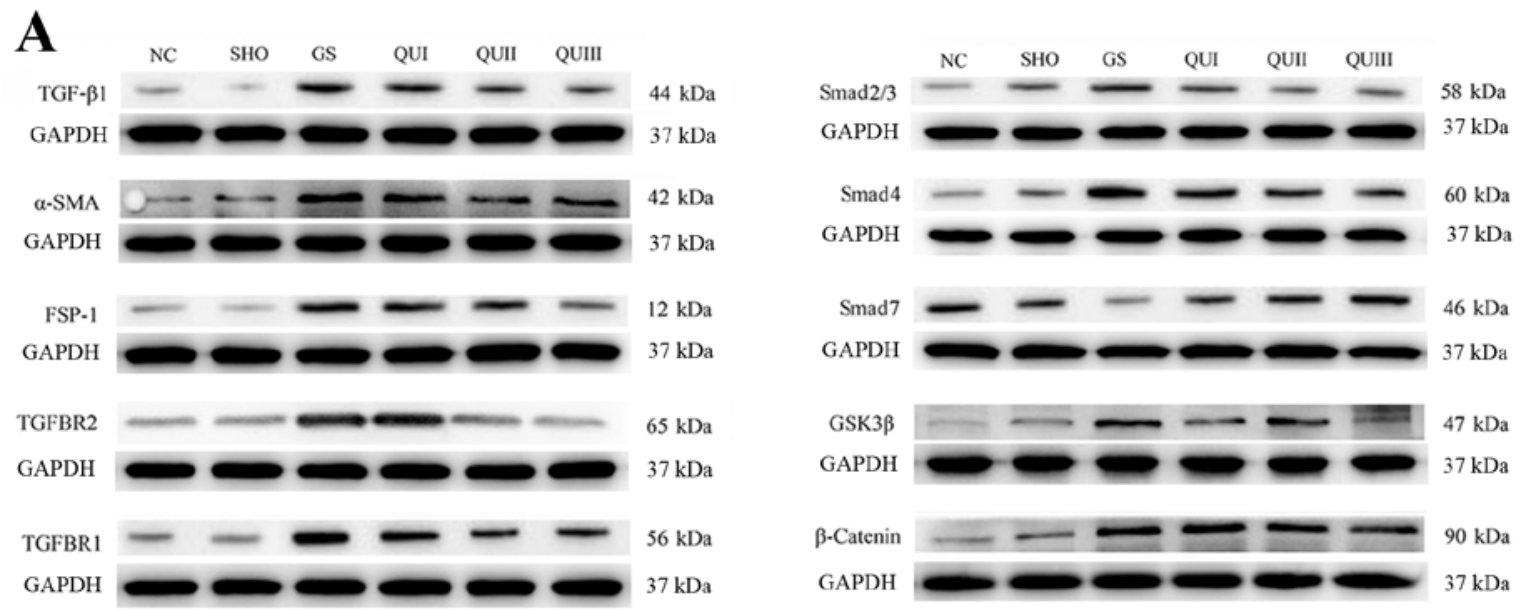

B
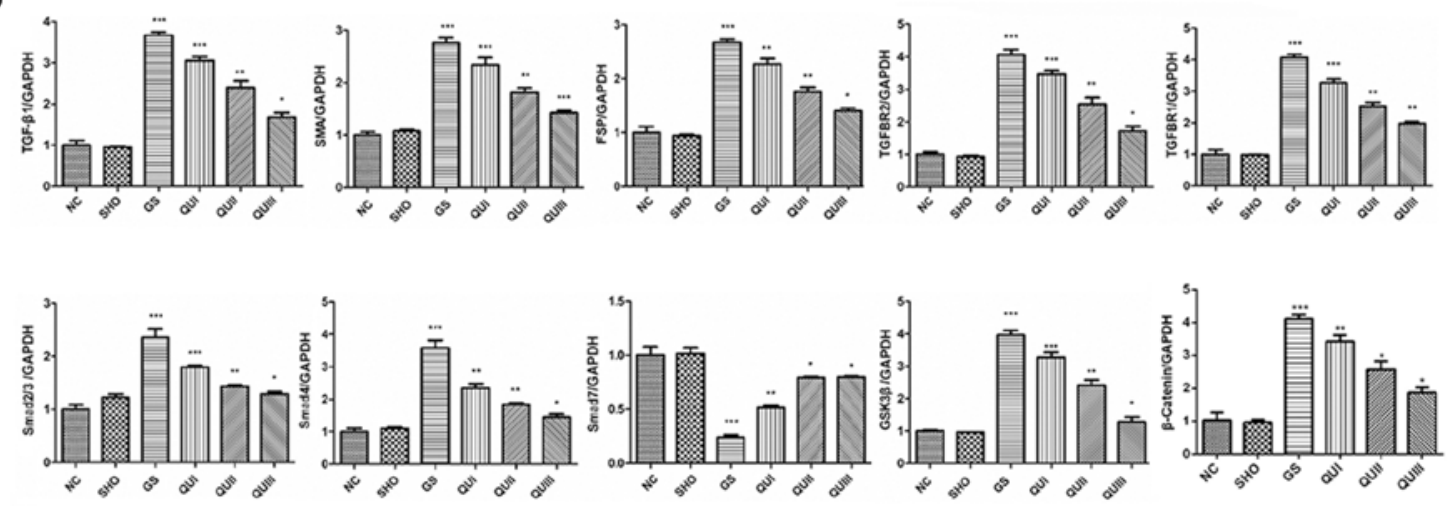

Figure 3. Protein expression levels of GS-associated proteins following QU intervention. (A) Western blotting of GS-associated proteins in rats from all groups . (B) Relative protein expression levels of GS-associated proteins in rats from all groups. Magnification, $\mathrm{x} 400$. All data are presented as the mean \pm standard deviation of the mean. ${ }^{*} \mathrm{P}<0.05,{ }^{* * *} \mathrm{P}<0.01$ and ${ }^{* * *} \mathrm{P}<0.001$, vs. the NC group. NC, normal control; SHO, sham operation group; GS, glomerulosclerosis; QU, quercetin; QU I, QU 25 mg/kg/day; QU II, $50 \mathrm{mg} / \mathrm{kg} / \mathrm{day}$; QU III, $100 \mathrm{mg} / \mathrm{kg} /$ day; TGF- $\beta$, transforming growth factor- $\beta$; ZO- 1 , zona occludens protein 1 ; SMA, smooth muscle actin; FSP-1, fibroblast-specific protein-1; TGFBR, transforming growth factor $\beta$ receptor; Smad, mothers against decapentaplegic homolog 9; GSK, glycogen synthase kinase.
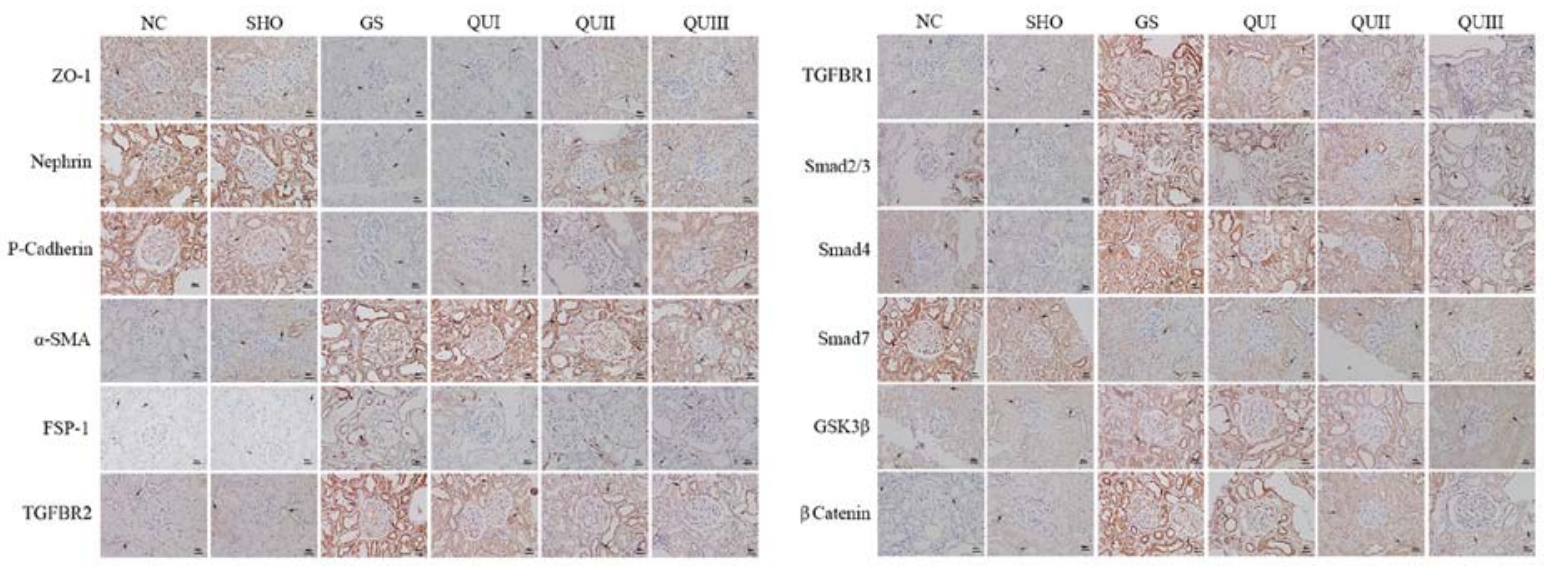

Figure 4. Detection of the distribution of GS-associated proteins by immunohistochemistry. Magnification, $\mathrm{x} 400$. Brown represents protein expression and increasingly dark colors represent increased protein expression. The arrows indicated the alterations in morphology. Scale bar, $5 \mu \mathrm{m}$. NC, normal control; SHO, sham operation group; GS, glomerulosclerosis; QU, quercetin; QU I, QU 25 mg/kg/day; QU II, 50 mg/kg/day; QU III, 100 mg/kg/day; ZO-1, zona occludens protein 1; SMA, smooth muscle actin; FSP-1, fibroblast-specific protein-1; TGFBR, transforming growth factor $\beta$ receptor; Smad, mothers against decapentaplegic homolog 9; GSK, glycogen synthase.

lead to tumorigenesis or tumor suppression $(33,34)$. It induces EMT to promote the invasion and metastasis of cancer cells (34). Disruption of the transcriptional network in the
EMT process can improve the tumor suppressive functions of TGF- $\beta$ (35). Myofibroblasts are characterized by their high expression of $\alpha$-SMA induced by elevated expression of 
TGF- $\beta 1$ receptors (36). The expression of FSP-1 is increased in a TGF- $\beta /$ Smad-dependent manner in systemic sclerosis skin. Additionally, FSP-1 overexpression or stimulation induced an activated phenotype in resting normal fibroblasts; however, knockdown of S100A4 attenuated the pro-fibrotic effects of TGF- $\beta$ (37). The expression level of the TGF- $\beta$ upstream target proteins GSK-3 $\beta$ (38) and $\beta$-catenin (39) were also significantly decreased by QU treatment of GS rats in the current study. Additionally, the expression levels of ZO-1 (40), Nephrin (41) and P-cadherin (42), which are podocyte marker proteins are negatively associated with podocyte apoptosis, were decreased in GS rats. Following treatment with QU, the expression of podocyte marker proteins (ZO-1, Nephrin and P-cadherin), TGF- $\beta$ signaling associated proteins (TGF- $\beta 1$, TGFBR1/2, Smad2/3, Smad4, Smad7, GSK-3 $\beta$ and $\beta$-catenin), EMT associated proteins ( $\alpha$-SMA and FSP-1) returned to normal levels. Following QU treatment, the development of EMT was attenuated in podocytes with GS, potentially via downregulating TGF- $\beta$ signaling proteins (TGF- $\beta 1$, TGFBR1/2, Smad2/3, Smad4, GSK-3 $\beta$ and $\beta$-catenin) and EMT proteins ( $\alpha$-SMA and FSP-1), and upregulating Smad7. This suggests that QU can protect the kidneys from GS by inhibiting the TGF- $\beta$ signal pathway.

In the present study, it was demonstrated that QU protects renal function and alleviates the progression of GS in rats. The mechanism may involve inhibition of the TGF- $\beta$ signaling pathway. QU is a natural flavonoid that is widely distributed in green plants, including fruits and vegetables. Although QU had some negative impact on embryonic development according to an in vitro study (43) and prenatal exposure resulted in a small increase in the risk of cancer in mice offspring (44), QU has been well tolerated in human studies. Doses up to $1,000 \mathrm{mg} /$ day did not produce adverse effects on blood parameters, liver and kidney function, hematology or serum electrolytes for several months (45-49). As a result of the low toxicity and side effects of QU, it may be clinically applicable. Therefore, this study suggests that QU can be used to treat GS. The present study used an in vivo rat model to demonstrate that QU treatment attenuates glomerulosclerosis via the TGF- $\beta$ signaling pathway, but lacked in vitro experiments. Therefore, the association between QU and TGF- $\beta$ signal pathway in vitro and the interference experiment of TGF- $\beta 1$ inhibition in QU treatment remains to be investigated.

\section{Acknowledgements}

Not applicable.

\section{Funding}

This work was supported by grants from the National Natural Science Foundation of China (grant no. 81360602), and the Science and Technology Development Project of Chengguan District, Gansu, Lanzhou (grant no. 2016-1-8).

\section{Availability of data and materials}

The datasets used and/or analyzed during the current study are available from the corresponding author on reasonable request.

\section{Author's contributions}

ED designed and supervised these experiments; YL performed most of experiments involved in this study, including the establishment of animal models, pathological section preparation, immunohistochemistry and so on, collated and analyzed the experimental data and wrote the manuscript; JY was responsible for the PCR and western blot analysis. All authors read and approved the final manuscript.

\section{Ethics approval and consent to participate}

The protocol was approved prior to commencing this study by the animal ethics committee of Gansu University of Chinese Medicine.

\section{Patient consent for publication}

Not applicable.

\section{Competing interest}

The authors declare that they have no competing interests.

\section{References}

1. Zou R, Xu G, Liu XC, Han M, Jiang JJ, Huang Q, He Y and Yao Y: PPARgamma agonists inhibit TGF-beta-PKA signaling in glomerulosclerosis. Acta Pharmacol Sin 31: 43-50, 2010.

2. Nagata M: Podocyte injury and its consequences. Kidney Int 89: 1221-1230, 2016.

3. Taneda S, Honda K, Ohno M, Uchida K, Nitta K and Oda $\mathrm{H}$ : Podocyte and endothelial injury in focal segmental glomerulosclerosis: An ultrastructural analysis. Virchows Arch 467: 449-458, 2015

4. Wang C, Blough E, Arvapalli R, Dai X, Triest WE, Leidy JW, Masannat $\mathrm{Y}$ and $\mathrm{Wu} \mathrm{M}$ : Acetaminophen attenuates glomerulosclerosis in obese Zucker rats via reactive oxygen species/p38MAPK signaling pathways. Free Radic Biol Med 81: 47-57, 2015

5. Qian Y, Feldman E, Pennathur S, Kretzler M and Brosius FC III: From fibrosis to sclerosis: Mechanisms of glomerulosclerosis in diabetic nephropathy. Diabetes 57: 1439-1445, 2008.

6. Zhou TB and Qin YH: The signaling pathways of LMX1B and its role in glomerulosclerosis. J Recept Signal Transduct Res 32: 285-289, 2012.

7. Hodgin JB, Bitzer M, Wickman L, Afshinnia F, Wang SQ, O'Connor C, Yang Y, Meadowbrooke C, Chowdhury M, Kikuchi M, et al: Glomerular aging and focal global glomerulosclerosis: A podometric perspective. J Am Soc Nephrol 26: 3162-3178, 2015.

8. Arauz J, Rivera-Espinoza Y, Shibayama M, Favari L, Flores-Beltrán RE and Muriel P: Nicotinic acid prevents experimental liver fibrosis by attenuating the prooxidant process. Int Immunopharmacol 28: 244-251, 2015.

9. Liu L, Lin W, Zhang Q, Cao W and Liu Z: TGF- $\beta$ induces miR-30d down-regulation and podocyte injury through $\mathrm{Smad} 2 / 3$ and HDAC3-associated transcriptional repression. J Mol Med (Berl) 94: 291-300, 2016.

10. Nabavi SF, Russo GL, Daglia $M$ and Nabavi SM: Role of quercetin as an alternative for obesity treatment: You are what you eat! Food Chem 179: 305-310, 2015.

11. Ma JQ, Li Z, Xie WR, Liu CM and Liu SS: Quercetin protects mouse liver against $\mathrm{CCl}_{4}$-induced inflammation by the TLR2/4 and MAPK/NF- $\mathrm{B}$ pathway. Int Immunopharmacol 28: 531-539, 2015.

12. Pan HC, Jiang Q, Yu Y, Mei JP, Cui YK and Zhao WJ: Quercetin promotes cell apoptosis and inhibits the expression of MMP-9 and fibronectin via the AKT and ERK signalling pathways in human glioma cells. Neurochem Int 80: 60-71, 2015. 
13. Baruah MM, Khandwekar AP and Sharma N: Quercetin modulates Wnt signaling components in prostate cancer cell line by inhibiting cell viability, migration, and metastases. Tumour Biol 37: 14025-14034, 2016.

14. Peng H, Liu Y, Wang J, Zhao X and Wang X: Effect of quercetin on the expression of TGF-beta1 in human embryonic lung fibroblasts activated by the silicotic alveolar macrophages. Wei Sheng Yan Jiu 42: 99-102, 2013 (In Chinese).

15. Steru L, Chermat R, Thierry B and Simon P: The tail suspension test: A new method for screening antidepressants in mice. Psychopharmacology (Berl) 85: 367-370, 1985.

16. Livak KJ and Schmittgen TD: Analysis of relative gene expression data using real-time quantitative PCR and the 2(-Delta Delta C(T)) method. Methods 25: 402-408, 2001.

17. Bertani T, Rocchi G, Sacchi G, Mecca G and Remuzzi G: Adriamycin-induced glomerulosclerosis in the rat. Am J Kidney Dis 7: 12-19, 1986.

18. Zhou TB, Qin YH, Lei FY, Su LN, Zhao YJ and Huang WF: apoE expression in glomerulus and correlation with glomerulosclerosis induced by adriamycin in rats. Ren Fail 33: 348-354, 2011.

19. Liu S, Jia Z, Zhou L, Liu Y, Ling H, Zhou SF, Zhang A, Du Y, Guan G and Yang T: Nitro-oleic acid protects against adriamycin-induced nephropathy in mice. Am J Physiol Renal Physiol 305: F1533-F1541, 2013.

20. Zhang YU, Zhou N, Wang H, Wang S and He J: Effect of Shenkang granules on the progression of chronic renal failure in 5/6 nephrectomized rats. Exp Ther Med 9: 2034-2042, 2015.

21. Zhou TB, Qin YH, Lei FY, Su LN, Zhao YJ and Huang WF: All-trans retinoic acid regulates the expression of apolipoprotein $\mathrm{E}$ in rats with glomerulosclerosis induced by Adriamycin. Exp Mol Pathol 90: 287-294, 2011.

22. Ding Y and Choi ME: Regulation of autophagy by TGF- $\beta$ : Emerging role in kidney fibrosis. Semin Nephrol 34: 62-71, 2014

23. Wan YG, Che XY, Sun W, Huang YR, Meng XJ, Chen HL, Shi XM, Tu Y, Wu W and Liu YL: Low-dose of multi-glycoside of Tripterygium wilfordii Hook. f., a natural regulator of TGF- $\beta 1 /$ Smad signaling activity improves adriamycin-induced glomerulosclerosis in vivo. J Ethnopharmacol 151: 1079-1089, 2014.

24. Fukuda A, Minakawa A, Sato Y,Iwakiri T, Iwatsubo S, Komatsu H, Kikuchi M, Kitamura K, Wiggins RC and Fujimoto S: Urinary podocyte and TGF- $\beta 1 \mathrm{mRNA}$ as markers for disease activity and progression in anti-glomerular basement membrane nephritis. Nephrol Dial Transplant 32: 1818-1830, 2017.

25. Yoon JJ, Lee YJ, Namgung S, Han BH, Choi ES, Kang DG and Lee HS: Samchuleum attenuates diabetic renal injury through the regulation of TGF- $\beta /$ Smad signaling in human renal mesangial cells. Mol Med Rep 17: 3099-3108, 2018

26. Kim YS, Xu ZG, Reddy MA, Li SL, Lanting L, Sharma K, Adler SG and Natarajan R: Novel interactions between TGF- $\{$ beta\} 1 actions and the 12/15-lipoxygenase pathway in mesangial cells. J Am Soc Nephrol 16: 352-362, 2005.

27. McKnight AJ, Savage DA, Patterson CC, Sadlier D and Maxwell AP: Resequencing of genes for transforming growth factor beta1 (TGFB1) type 1 and 2 receptors (TGFBR1, TGFBR2), and association analysis of variants with diabetic nephropathy. BMC Med Genet 8: 5, 2007.

28. Das F, Ghosh-Choudhury N, Bera A, Dey N, Abboud HE, Kasinath BS and Choudhury GG: Transforming growth factor $\beta$ integrates Smad 3 to mechanistic target of rapamycin complexes to arrest deptor abundance for glomerular mesangial cell hypertrophy. J Biol Chem 288: 7756-7768, 2013.

29. Zhang L, Liu C, Meng XM, Huang C, Xu F and Li J: Smad2 protects against TGF- $\beta 1 / \mathrm{Smad} 3$-mediated collagen synthesis in human hepatic stellate cells during hepatic fibrosis. Mol Cell Biochem 400: 17-28, 2015.

30. Yang H, Li G, Wu JJ, Wang L, Uhler M and Simeone DM: Protein kinase A modulates transforming growth factor- $\beta$ signaling through a direct interaction with Smad4 protein. J Biol Chem 288: 8737-8749, 2013.

31. Schiffer M, Bitzer M, Roberts IS, Kopp JB, ten Dijke P, Mundel P and Böttinger EP: Apoptosis in podocytes induced by TGF-beta and Smad7. J Clin Invest 108: 807-816, 2001.
32. Larsson SO, Hedner U and Nilsson IM: On fibrinolytic split products in serum and urine in uraemia. Scand J Urol Nephrol 5: 234-242, 1971.

33. Guasch G, Schober M, Pasolli HA, Conn EB, Polak L and Fuchs E: Loss of TGFbeta signaling destabilizes homeostasis and promotes squamous cell carcinomas in stratified epithelia. Cancer Cell 12: 313-327, 2007.

34. Heldin $\mathrm{CH}$, Vanlandewijck M and Moustakas A: Regulation of EMT by TGF $\beta$ in cancer. FEBS Lett 586: 1959-1970, 2012.

35. David CJ, Huang YH, Chen M, Su J, Zou Y, Bardeesy N, Iacobuzio-Donahue CA and Massagué J: TGF- $\beta$ tumor suppression through a lethal EMT. Cell 164: 1015-1030, 2016.

36. Sriram S, Gibson DJ, Robinson P, Pi L, Tuli S, Lewin AS and Schultz G: Assessment of anti-scarring therapies in ex vivo organ cultured rabbit corneas. Exp Eye Res 125: 173-182, 2014.

37. Tomcik M, Palumbo-Zerr K, Zerr P, Avouac J, Dees C, Sumova B, Distler A, Beyer C, Cerezo LA, Becvar R, et al: S100A4 amplifies TGF- $\beta$-induced fibroblast activation in systemic sclerosis. Ann Rheum Dis 74: 1748-1755, 2015.

38. Yan Q, Luo H, Wang B, Sui W, Zou G, Chen H and Zou H: Correlation between PKB/Akt, GSK-3 $\beta$ expression and tubular epithelial-mesenchymal transition in renal allografts with chronic active antibody-mediated rejection. Exp Ther Med 13: 2217-2224, 2017

39. Toraldo G, Bhasin S, Bakhit M, Guo W, Serra C, Safer JD, Bhawan $\mathrm{J}$ and Jasuja R: Topical androgen antagonism promotes cutaneous wound healing without systemic androgen deprivation by blocking $\beta$-catenin nuclear translocation and cross-talk with TGF- $\beta$ signaling in keratinocytes. Wound Repair Regen 20: $61-73,2012$.

40. Wagner MC, Rhodes G, Wang E, Pruthi V, Arif E, Saleem MA, Wean SE, Garg P, Verma R, Holzman LB, et al: Ischemic injury to kidney induces glomerular podocyte effacement and dissociation of slit diaphragm proteins Neph1 and ZO-1. J Biol Chem 283: 35579-35589, 2008.

41. Jia J, Ding G, Zhu J, Chen C, Liang W, Franki N and Singhal PC: Angiotensin II infusion induces nephrin expression changes and podocyte apoptosis. Am J Nephrol 28: 500-507, 2008.

42. Teixeira Vde P, Blattner SM, Li M, Anders HJ, Cohen CD, Edenhofer I, Calvaresi N, Merkle M, Rastaldi MP and Kretzler M: Functional consequences of integrin-linked kinase activation in podocyte damage. Kidney Int 67: 514-523, 2005.

43. Pérez-Pastén R, Martinez-Galero E and Chamorro-Cevallos G: Quercetin and naringenin reduce abnormal development of mouse embryos produced by hydroxyurea. J Pharm Pharmacol 62: 1003-1009, 2010.

44. Vanhees K, de Bock L, Godschalk RW, van Schooten FJ and van Waalwijk van Doorn-Khosrovani SB: Prenatal exposure to flavonoids: Implication for cancer risk. Toxicol Sci 120: 59-67, 2011.

45. Heinz SA, Henson DA, Austin MD, Jin F and Nieman DC: Quercetin supplementation and upper respiratory tract infection: A randomized community clinical trial. Pharmacol Res 62 237-242, 2010.

46. Jin F, Nieman DC, Shanely RA, Knab AM, Austin MD and Sha W: The variable plasma quercetin response to 12 -week quercetin supplementation in humans. Eur J Clin Nutr 64: 692-697, 2010.

47. Nieman DC, Henson DA, Davis JM, Dumke CL, Gross SJ, Jenkins DP, Murphy EA, Carmichael MD, Quindry JC, McAnulty SR, et al: Quercetin ingestion does not alter cytokine changes in athletes competing in the western states endurance run. J Interferon Cytokine Res 27: 1003-1011, 2007.

48. Scholten SD and Sergeev IN: Long-term quercetin supplementation reduces lipid peroxidation but does not improve performance in endurance runners. Open Access J Sports Med 4: 53-61, 2013.

49. Shanely RA, Knab AM, Nieman DC, Jin F, McAnulty SR and Landram MJ: Quercetin supplementation does not alter antioxidant status in humans. Free Radic Res 44: 224-231, 2010.

This work is licensed under a Creative Commons Attribution-NonCommercial-NoDerivatives 4.0 International (CC BY-NC-ND 4.0) License. 